\title{
los problemas del polvo y del desempolvado en los hornos verticales de cemento
} staub-und entstaubungsfragen der zementschachtöfen

G. FUNKE

La eliminación de las partículas gruesas de polvo es posible por medio de cámaras de decantación, de extractores centrífugos (ciclones) o por vía húmeda: Los ciclones sólo dan buen resultado si, bajo las condiciones de operación continuada, los gases pueden mantenerse con garantía a una temperatura superior a la del punto de rocío.

Para eliminar los polvos finos es necesario emplear filtros eléctricos o desempolvadores por vía húmeda de alta calidad. Debe demostrarse con la práctica hasta qué punto es útil con este fin el filtro MB (de la casa M. Berz de Kochel). Hasta la fecha no han resultado satisfactorios los filtros de tejido, pero se están desarrollando nuevos materiales con este fin.

Los filtros eléctricos de vía seca trabajan sin inconveniente alguno, sólo si la temperatura de los gases de hornos verticales de cemento está muy por encima del punto de rocío, para que de ningún modo pueda condensar el agua en la planta de precipitación. Para conseguir esto es necesario, a veces, dar a los hornos un diseño especial y cocer con un método adecuado o bien conducir los gases a un conducto común para ser recalentados.

Es absolutamente necesario reducir al mínimo la cantidad de aire «falso» que entra por la cabeza del horno para mantener alta la temperatura de los gases de escape sin necesidad de precalentamiento.

Los filtros por vía húmeda y los precipitadores electrostáticos de vía húmeda son independientes de la temperatura de los gases. Sin embargo, los primeros tienen un consumo elevado de energía. El consumo de agua para estos filtros es poco corriente en la industria del cemento y puede crear dificultades (consumo de agua, álcalis, leyes sobre el agua empleada, etc.). Por ello es necesario esperar y ver cómo estos sistemas de desempolvado se introducen y prueban satisfactoriamente en la industria del cemento. 